\title{
Knowledge and Practice of Health Professionals in the Management of Dysphagia
}

\author{
Eduardo Sánchez-Sánchez ${ }^{1, *}$, Ylenia Avellaneda-López ${ }^{1}$, Esperanza García-Marín ${ }^{1}$, Guillermo Ramírez-Vargas ${ }^{1}$, \\ Jara Díaz-Jimenez ${ }^{2}$ and Francisco Javier Ordonez ${ }^{3}$ \\ 1 Internal Medicine Department, Punta de Europa Hospital, Algeciras, 11207 Cádiz, Spain; \\ ain3ly@gmail.com (Y.A.-L.); espe_garciamarin@hotmail.com (E.G.-M.); guiram1992@gmail.com (G.R.-V.) \\ 2 Faculty of Education Sciences, University of Cádiz, 11519 Puerto Real, Spain; luna_nueva17@hotmail.com \\ 3 Human Anatomy, School of Medicine, University of Cádiz, Plaza Fragela s/n, 11003 Cádiz, Spain; \\ franciscojavier.ordonez@uca.es \\ * Correspondence: eduardo.sanchez.sanchez.sspa@juntadeandalucia.es; Tel.: +34-671-569-320
}

check for

updates

Citation: Sánchez-Sánchez, E.; Avellaneda-López, Y.; García-Marín,

E.; Ramírez-Vargas, G.; Díaz-Jimenez,

J.; Ordonez, F.J. Knowledge and

Practice of Health Professionals in the Management of Dysphagia. Int. J. Environ. Res. Public Health 2021, 18, 2139. https://doi.org/10.3390/ ijerph18042139

Academic Editor: Paul B. Tchounwou

Received: 5 January 2021

Accepted: 17 February 2021

Published: 22 February 2021

Publisher's Note: MDPI stays neutral with regard to jurisdictional claims in published maps and institutional affiliations.

Copyright: (c) 2021 by the authors. Licensee MDPI, Basel, Switzerland. This article is an open access article distributed under the terms and conditions of the Creative Commons Attribution (CC BY) license (https:/ / creativecommons.org/licenses/by/ $4.0 /)$.

\begin{abstract}
The aim of this study was to determine healthcare providers' knowledge and practices about dysphagia. A descriptive cross-sectional study was carried out based on a self-administered and anonymous questionnaire addressed to healthcare providers in Spain. A total of 396 healthcare providers participated in the study. Of these, $62.3 \%$ knew the definition of dysphagia as a swallowing disorder. In addition, up to $39.2 \%$ of the participants reported that they did not know whether the EatingAssessmentTool (EAT-10) dysphagia screening test was usedin their own clinical settings. Similarly, up to $49.1 \%$ of them did not know the ClinicalExaminationVolume-Viscosity (MECVV) method. Nearly all participants $(98.8 \%)$ reported that thickeners must be used forall liquids administered to patients. A higher percentage of respondents based the choice of texture on patient's tolerance $(78.2 \%)$ rather than on the MECV-V result (17.3\%). In addition,76.4\% of the professionals had witnessed a bronchoaspiration; after it, $44.4 \%(n=175)$ of them reported the appearance of pneumonia, and $14.5 \%(n=57)$ the death of the patient $(p=0.005)$. The participants revealeda moderate/low knowledge ofthe definition, diagnosis, and clinical management of liquid dysphagia, which indicates some room for improvements.
\end{abstract}

Keywords: bronchoaspiration; dysphagia; MECV-V; pneumonia; health professionals

\section{Introduction}

Nutrition is a basic function of the living being, carried out involuntarily for the acquisition of the necessary nutrients for the correct functioning of the organism. Nutrition starts with the processing of food in the mouth, which involves chewing, formation of abolus, and swallowing, and continues with the bolus being transported to the digestive tract where digestion and subsequent absorption of the different nutrients will take place. It is for this reason that swallowing is an important step in obtaining the body's requirements and needs in a safe and effective way [1]. The digestive tract runs parallel to the respiratory one, and the two share anatomical structures; therefore, swallowing must be carried out in a coordinated manner, so that food cannot enter the airway [2].

Dysphagia or impaired swallowing refers to difficulties in any of the three main phases of the swallowing process, i.e., the oral, pharyngeal, and oesophageal phases [3]. Dysphagia can appear with solid or liquid intake.

It is widely accepted that it is a prevalent disorder among older adults. In fact, signs of dysphagia were common among patients aged 65 years or older in acute care settings [4,5]. The current situation could be even worse in the institutionalized elderly population [6]. Swallowing inefficiency could also be prevalent in younger individuals with amyotrophic lateral sclerosis [7]. 
The consequences of fluid dysphagia include tracheobronchial aspiration [8]. Although some clinical signs, like coughing, help in the diagnosis of aspiration, silent aspiration may occur [9], which, being asymptomatic, may remain undetected by observation [10]. This may lead to aspiration pneumonia [8]. Pneumonia is one of the main causes of mortality after a stroke [11,12]. Dysphagia patients have a higher rate of pneumonia compared to those without dysphagia ( $29.7 \%$ vs. $3.7 \%$ ). Dysphagia can reduce patients' quality of life and increase hospital stays, socio-sanitary charges, and the risk of mortality [13-15]. Limited food and fluid intake, as well as abuse of fast to avoid aspiration in patients with liquid dysphagia, are risk factors for the onset of malnutrition and dehydration [16].

The care of patients with liquid dysphagia aims to reduce the complications derived from this condition. It is recommended to adopt some general measures. These measures include the adaptation of food texture and viscosity according to the degree of dysphagia present, avoiding foods with two textures, especially for patients with liquid dysphagia, avoiding the use of syringes and of straws for the oral administration of liquids, as they do not stimulate swallowing and promote aspiration, placing and maintaining the patient in a suitable position before and during ingestion, adapting the kitchenware to the patient's needs [17].

Liquid dysphagia is one of the most underdiagnosed disorders by health professionals [1]. The lack of diagnosis is associated with negative outcomes, which leads to the increase of hospital stays, socio-health costs, and one-year mortality $[15,18,19]$. For dysphagia patients, the hospital costs directly associated with dysphagia amount to 3677 euros, and those associated with home care to 6192 euros [20].

Clinical bedside assessment may be helpful for the diagnosis of dysphagia and its severity; however silent aspirations cannot be detected. For the diagnosis of silent dysphagia, tests must be used, being the Video fluoroscopic swallowing studies the gold standard for its diagnosis [21]. There are different clinical methods for the screening and diagnosis of liquid dysphagia, among which the screening methods based on the Eating Assessment Tool (EAT-10) and on the Clinical Examination of Volume Viscosity (MECV-V) [22]. The EAT-10 is a simple and fast method that evaluates the presence of specific symptoms of dysphagia and has been shown to have high internal consistency and reproducibility [23].

The MECV-V is a valid and reliable screening test [24]. It has high sensitivity and specificity [25] for the detection of dysphagia [26]. It is based on a detailed protocol designed to maintain the safety and efficacy of swallowing and detect silent aspirations [27]. It allows establishing the diagnosis of dysphagia and guiding dietary adaptations so that swallowing becomes safe and effective. This method evaluates the presence of three different types of food texture on the basis of their viscosity-i.e., liquid, nectar, and pudding - in three volumes $(5 \mathrm{~mL}, 10 \mathrm{~mL}$, and $20 \mathrm{~mL})$ [28]. Changes in any of the signs associated with safety (voice tone, cough, or oxygen desaturation) or efficacy (lip seal, oral residue, fractional swallowing, and pharyngeal residue) label the test positive [22].

Recent studies have pointed out that a multidisciplinary team approach was important to properly identify and manage dysphagia $[29,30]$. However, the full team (doctors, physical therapists, speech therapists, rehabilitators, nurses, auxiliary nursing care technicians (ANCTs)) may not be available in all clinical settings, and thus isolated healthcare providers should deal with dysphagia. As a consequence, the knowledge of these professionals about dysphagia management are essential for the appropriate continuing professional development in this area [29].

This study was aimed to determine the knowledge and practices of Spanish healthcare providers (nurses, doctors, ANCTs) who care for patients with liquid dysphagia or at risk of suffering from it. This information may play a key role when preparing future clinical training programs and detailed algorithms for the clinical management of dysphagia.

\section{Materials and Methods}

A cross-sectional descriptive study based on an anonymous and self-administered questionnaire was conducted for nurses working in any field of health. The current 
online medical questionnaire was administered on a free platform (Google) [31]. A nonprobabilistic or convenience sample was used, since the questionnaire was open to all nurses, doctors, and ANCTs who carried out their healthcare activity in Spain.

In order to estimate the sample size, we considered the last report of the National Health System established in 2017, which stated that there were 245,533 nurses and 178,600 doctors in Spain [32]. For ANCTs, figures were not included, but a total of 120, 110 has been estimated [33]. Accordingly, a total of 544,243 health professionals worked in Spain in 2017. Accordingly, the current sample size $(n=384)$ was calculated assuming $95 \%$ confidence level or $5 \%$ level of significance and a $10 \%$ margin of error.

No standardized questionnaire on healthcare providers' knowledge and practices about dysphagia was found in the literature. Therefore, we designed a semi-structured questionnaire, based on the doubts and questions of healthcare professionals who had access to training courses delivered nationally by the authors in the last 2 years. A pilot study was carried out among colleagues from our unit and others who had received training to check the effectiveness of the questionnaire, in order to know if it provided us with the necessary information and if we should modify any questions. After this, questions were modified when they were not sufficiently understandable, which could lead to an interpretation error.

The first part of the questionnaire included sociodemographic variables such as age, sex, province of residence, and unit where the professionals carry out their activity. The second part included questions about diagnosis, management, recommendations, and complications regarding dysphagia. Lastly, in order to guarantee the dissemination of the questionnaire among Spanish healthcare providers, social platforms such as Twitter, Facebook, WhatsApp, and Instagram were used. The questionnaire was administered between March and June 2019.

All data obtained from the questionnaire were represented descriptively. The qualitative variables were their frequency and percentage, and the quantitative variables were expressed by the mean and the standard deviation or dispersion. Subsequently and by the use ofthe Chi-square test, significant differences between different groups were assessed, assuming a confidence level of $95 \%$. Significance was set at an alpha level of 0.05 . Statistical treatment was conducted using the free R-Commander package.

\section{Results}

A total of 400 responses to the questionnaire were obtained, but 6 were deleted because of missing data for some responses. Of the 396 subjects studied, $82.5 \%$ were women $(n=325)$, and $17.5 \%$ were men $(n=69)$. The mean age of the respondents was $39.4 \pm 9.3$ years ( $39.1 \pm 9.5$ years for women; $40.4 \pm 8.1$ years for men).

The professional category with the highest representation in the sample was nursing staff, corresponding to $82.2 \%(n=324)$, followed by ANCT $(13.9 \%, n=55)$ and doctors $(3.8 \%, n=15)(p<0.001)$.

As the data collection was carried out through social network platforms, participants responded from the whole country (Spain). With regard to Autonomous Communities, Andalusia was the most represented, with $44.6 \%(n=176)$ of participants, followed by the Balearic Islands $(12.4 \%, n=49)$, Madrid $(10.1 \%, n=40)$, and Catalonia $(6.3 \%, n=25)$. The least represented were Cantabria and Murcia, with $0.76 \%(n=3)$ and $0.3 \%(n=1)$ of participants, respectively.

Regarding the assistance units or departments, the most represented in the current study were Internal Medicine $(n=97 ; 24.6 \%)$, Geriatrics $(n=43 ; 10.9 \%)$, and Primary Care $(39 ; 9,9 \%)$, with the professionals of the Social Health Centers being the least prevalent $(n=6 ; 1.5 \%)$. The other category included units such as urology, cardiology, pneumology, etc. Of the subjects surveyed, $45.7 \%(n=180)$ answered that there were Nutrition Units in their centers, whereas $18.0 \%$ did not know if these units were present in their centers.

Up to $63.2 \%(n=249)$ of the respondents reported that they knew the definition of dysphagia, there being no statistically significant differences between the different 
professional categories $(p=0.350)$. A contingency table was defined for two variables, one of them being the unit of work, and the other the knowledge of the definition of dysphagia. The results showed that a higher percentage of emergency professionals $(n=21 ; 87.5 \%)$, than of those who worked in socio-health centers $(n=1 ; 16.7 \%)$ defined dysphagia, with differences statistically significant between the different units or services $(p<0.001)$. There were no statistically significant differences in the definition of dysphagia between the professionals when considering the presence or absence of Nutrition Units in their centers $(p=0.107)($ Table 1$)$.

Table 1. Work units and presence of Nutrition Units.

\begin{tabular}{|c|c|c|c|c|c|}
\hline & \multirow[b]{2}{*}{$n$} & \multirow[b]{2}{*}{$\%$} & \multicolumn{2}{|c|}{ Definition of Dysphagia } & \multirow{2}{*}{$p$-Value } \\
\hline & & & $\begin{array}{c}\text { Impaired } \\
\text { Swallowing }(n, \%)\end{array}$ & $\begin{array}{c}\text { Do Not Know } \\
n(\%)\end{array}$ & \\
\hline \multicolumn{6}{|l|}{ Reference Units: } \\
\hline Surgical area & 20 & 5.5 & $12(60.0)$ & $8(40.0)$ & \multirow{12}{*}{$<0.001$} \\
\hline $\begin{array}{l}\text { Primary Health } \\
\text { Care }\end{array}$ & 39 & 9.9 & $30(6.9)$ & $9(23.1)$ & \\
\hline $\begin{array}{l}\text { Socio-Health } \\
\text { centers }\end{array}$ & 6 & 1.5 & $1(16.7)$ & $5(83.3)$ & \\
\hline $\begin{array}{l}\text { Critical Care } \\
\text { Medicine }\end{array}$ & 26 & 6.6 & $16(61.5)$ & $10(38.5)$ & \\
\hline Palliative Care & 10 & 2.6 & $8(0.0)$ & $2(20.0)$ & \\
\hline Geriatrics & 43 & 10.9 & $34(79.1)$ & $9(20.9)$ & \\
\hline Internal Medicine & 97 & 24.6 & $49(50.5)$ & $48(49.5)$ & \\
\hline Neurology & 15 & 3.8 & $7(46.7)$ & $8(53.3)$ & \\
\hline Oncology & 31 & 7.9 & $14(45.2)$ & $17(54.8)$ & \\
\hline Otorhinolaryngology & 7 & 1.8 & $5(71.4)$ & $2(28.6)$ & \\
\hline Emergency & 24 & 6.1 & $21(87.5)$ & $3(12.5)$ & \\
\hline Others & 76 & 19.3 & $52(68.4)$ & $24(3.6)$ & \\
\hline \multicolumn{6}{|l|}{$\begin{array}{l}\text { Nutrition Unit in } \\
\text { the center: }\end{array}$} \\
\hline Yes & 180 & 45.7 & $123(54.9)$ & $57(45.1)$ & \multirow{3}{*}{0.107} \\
\hline Not & 143 & 36.3 & $87(60.8)$ & $56(39.2)$ & \\
\hline Do not know & 71 & 18 & $39(68.3)$ & $52(31.7)$ & \\
\hline
\end{tabular}

The data obtained on health professionals' knowledge and management of liquid dysphagia is detailed by groups in Table 2. The approach to a patient with dysphagia through the performance of a test was the most prevalent response $(57.9 \%, n=228)$, with respect to the prohibition of fluid intake $(n=12 ; 3.0 \%)$ and the application of absolute diet guidelines $(n=5 ; 1.3)$. Conversely, 37.8\% $(n=149)$ of respondents reported not knowing which approach should be taken with these patients. No significant differences were found between groups $(p=0.130)$.

Table 2. Health professionals'knowledge and management of patients with liquid dysphagia.

\begin{tabular}{|c|c|c|c|c|c|}
\hline $\begin{array}{l}\text { Questionnaire/Answer } \\
\text { to the Questionnaire }\end{array}$ & $\begin{array}{c}\text { Nurse }(\mathrm{N}=324) \\
\text { n }(\%)\end{array}$ & $\begin{array}{c}\text { Doctor }(\mathrm{N}=15) \\
\mathrm{n}(\%)\end{array}$ & $\begin{array}{c}\text { ANCT }(\mathrm{N}=55) \\
\text { n }(\%)\end{array}$ & $\begin{array}{c}\text { Total }(\mathrm{N}=394) \\
\mathrm{n}(\%)\end{array}$ & $p$-Value \\
\hline \multicolumn{6}{|l|}{$\begin{array}{c}\text { What is the definition } \\
\text { of dysphagia? }\end{array}$} \\
\hline Impaired swallowing & $210(64.8)$ & $8(53.3)$ & $31(56.4)$ & $249(63.2)$ & 0.35 \\
\hline Do not know & $114(35.2)$ & $7(46.7)$ & $24(43.6)$ & $165(36.8)$ & \\
\hline
\end{tabular}


Table 2. Cont.

\begin{tabular}{|c|c|c|c|c|c|}
\hline $\begin{array}{l}\text { Questionnaire/Answer } \\
\text { to the Questionnaire }\end{array}$ & $\begin{array}{c}\text { Nurse }(\mathrm{N}=324) \\
n(\%)\end{array}$ & $\begin{array}{c}\text { Doctor }(\mathrm{N}=15) \\
n(\%)\end{array}$ & $\begin{array}{c}\text { ANCT (N = 55) } \\
\text { n (\%) }\end{array}$ & $\begin{array}{c}\text { Total }(\mathrm{N}=394) \\
\text { n (\%) }\end{array}$ & $p$-Value \\
\hline \multicolumn{6}{|l|}{$\begin{array}{l}\text { What approach would } \\
\text { you take witha patient } \\
\text { with liquid dysphagia? }\end{array}$} \\
\hline $\begin{array}{l}\text { Dysphagia test and } \\
\text { adaptation of the diet }\end{array}$ & 194 (59.9) & $8(53.3)$ & $26(47.3)$ & $228(57.9)$ & \multirow{4}{*}{0.13} \\
\hline No fluid intake & $8(2.5)$ & $0(0.0)$ & $4(7.3)$ & $12(3.0)$ & \\
\hline Absolute diet & $3(0.9)$ & $1(6.7)$ & $1(1.8)$ & $5(1.3)$ & \\
\hline Do not know & $119(36.7)$ & $6(40.0)$ & $24(43.6)$ & $149(37.8)$ & \\
\hline \multicolumn{6}{|l|}{$\begin{array}{l}\text { Is the EAT-10 test } \\
\text { performed at your } \\
\text { center? }\end{array}$} \\
\hline Yes & $64(19.8)$ & $3(20.0)$ & $15(27.3)$ & $82(20.8)$ & \multirow{3}{*}{0.136} \\
\hline Not & $73(22.5)$ & $2(13.3)$ & $4(7.3)$ & $79(20.0)$ & \\
\hline I do not know the test & $127(39.2)$ & $5(33.3)$ & $22(40.0)$ & 154 (39.2) & \\
\hline Do not know & $60(28.5)$ & $5(33.3)$ & $14(25.5)$ & $79(20.0)$ & \\
\hline \multicolumn{6}{|l|}{$\begin{array}{l}\text { Is the MEDCV-V test } \\
\text { performed at your } \\
\text { center? }\end{array}$} \\
\hline Yes & $83(25.6)$ & $3(20.0)$ & $9(16.4)$ & $95(24.1)$ & \multirow{4}{*}{0.008} \\
\hline Not & $57(17.6)$ & $2(13.3)$ & $2(3.6)$ & $61(15.5)$ & \\
\hline I do not know the test & $132(40.7)$ & $4(26.7)$ & $29(52.7)$ & $165(41.9)$ & \\
\hline Do not know & $52(16.0)$ & $6(40.0)$ & $15(27.3)$ & $73(18.5)$ & \\
\hline \multicolumn{6}{|l|}{$\begin{array}{l}\text { When are these tests } \\
\text { performed? }\end{array}$} \\
\hline Upon admission & $46(14.2)$ & $2(14.2)$ & $11(20.0)$ & $59(15.0)$ & \multirow{5}{*}{0.382} \\
\hline On request & $43(13.3)$ & $4(26.7)$ & $4(7.3)$ & $51(12.9)$ & \\
\hline $\begin{array}{l}\text { With people at risk of } \\
\text { dysphagia }\end{array}$ & $136(42.0)$ & $6(40.0)$ & $21(38.2)$ & $163(41.4)$ & \\
\hline After bronchoaspiration & $9(2.8)$ & $0(0.0)$ & $4(7.3)$ & $13(3.3)$ & \\
\hline \multirow{2}{*}{\multicolumn{6}{|c|}{$\begin{array}{l}\text { Do not know } \\
\text { Are subsequent checks } \\
\text { carried out? }\end{array}$}} \\
\hline & & & & & \\
\hline Yes & $136(42.0)$ & $6(40.0)$ & $24(43.6)$ & $166(42.1)$ & \multirow{3}{*}{0.85} \\
\hline Not & $53(16.4)$ & $4(26.7)$ & $8(14.5)$ & $65(16.5)$ & \\
\hline Do not know & 135 (41.7) & $5(33.3)$ & $23(41.8)$ & $163(41.4)$ & \\
\hline \multicolumn{6}{|l|}{$\begin{array}{l}\text { Who carries out these } \\
\text { tests? }\end{array}$} \\
\hline Doctor & $21(6.5)$ & $4(26.7)$ & $8(14.5)$ & $3(0,8)$ & \multirow{7}{*}{0.114} \\
\hline Nurse & 117 (36.1) & $2(13.3)$ & 19 (34.5) & $138(35.0)$ & \\
\hline Speech therapist & $8(2.5)$ & $0(0.0)$ & $0(0.0)$ & $8(2.0)$ & \\
\hline Nutrition unit & $46(14.2)$ & $4(26.7)$ & $11(20.0)$ & 61 (15.5) & \\
\hline Other & $4(1.2)$ & $0(0.0)$ & $1(1.8)$ & $5(1.3)$ & \\
\hline Do not know & $126(38.9)$ & $5(33.3)$ & $16(29.1)$ & $147(37.3)$ & \\
\hline Not applicable & $2(0.6)$ & $0(0.00)$ & $0(0.0)$ & $2(0.5)$ & \\
\hline \multirow{2}{*}{\multicolumn{6}{|c|}{$\begin{array}{l}\text { If the patient requires } \\
\text { thickeners, when is the } \\
\text { thickener used? }\end{array}$}} \\
\hline & & & & & \multirow{3}{*}{0.317} \\
\hline $\begin{array}{l}\text { Lunch } \\
\text { - }\end{array}$ & $3(0.9)$ & $0(0.0)$ & $0(0.0)$ & $3(0.8)$ & \\
\hline Dinner & $1(0.3)$ & $0(0.0)$ & $0(0.0)$ & $1(0.2)$ & \\
\hline \multicolumn{6}{|l|}{$\begin{array}{l}\text { In all fluids the patients } \\
\text { ingest }\end{array}$} \\
\hline \multicolumn{6}{|l|}{$\begin{array}{l}\text { Based on whatdo you } \\
\text { choose the texture to be } \\
\text { prescribed topatients } \\
\text { with liquid dysphagia? }\end{array}$} \\
\hline MECV-V test results & $59(18.2)$ & $3(20.0)$ & $6(10.9)$ & $68(17.3)$ & \multirow{3}{*}{0.497} \\
\hline Patient tolerance & $249(76.9)$ & $11(73.3)$ & $48(87.3)$ & 308 (78.2) & \\
\hline Palatability & $16(4.9)$ & $1(6.7)$ & $1(1.8)$ & $18(4.5)$ & \\
\hline \multirow{2}{*}{\multicolumn{6}{|c|}{$\begin{array}{l}\text { Do you adjust the } \\
\text { position ofapatient } \\
\text { with liquid dysphagia } \\
\text { before eating? }\end{array}$}} \\
\hline & & & & & \\
\hline $\begin{array}{l}\text { before eating? } \\
\text { Yes, always }\end{array}$ & $301(92.9)$ & $10(66.7)$ & $54(98.2)$ & $365(92.6)$ & \multirow{4}{*}{$<0.001$} \\
\hline Often & $21(6.5)$ & $3(20.0)$ & $1(1.8)$ & $25(6.4)$ & \\
\hline Rarely & $1(0.3)$ & $2(13.3)$ & $0(0.0)$ & $3(0.8)$ & \\
\hline Never & $1(0.3)$ & $0(0.0)$ & $0(0.0)$ & $1(0.2)$ & \\
\hline Do you provide straws & & & & & \\
\hline $\begin{array}{l}\text { or syringes for the } \\
\text { administration of }\end{array}$ & & & & & \\
\hline liquid topatients with & & & & & \\
\hline liquid dysphagia? & & & & & \\
\hline Yes & $190(58.6)$ & $9(60.0)$ & $42(76.4)$ & $244(61.2)$ & 0.044 \\
\hline Not & 134 (41.4) & $6(40.0)$ & $13(23.6)$ & $153(38.8)$ & \\
\hline
\end{tabular}


Table 2. Cont.

\begin{tabular}{|c|c|c|c|c|c|}
\hline $\begin{array}{l}\text { Questionnaire/Answer } \\
\text { to the Questionnaire }\end{array}$ & $\begin{array}{c}\text { Nurse }(\mathrm{N}=324) \\
\text { n (\%) }\end{array}$ & $\begin{array}{c}\text { Doctor }(\mathrm{N}=15) \\
n(\%)\end{array}$ & $\begin{array}{c}\text { ANCT }(\mathrm{N}=55) \\
\text { n (\%) }\end{array}$ & $\begin{array}{c}\text { Total }(\mathrm{N}=394) \\
\mathrm{n}(\%)\end{array}$ & $p$-Value \\
\hline \multicolumn{6}{|l|}{$\begin{array}{c}\text { Do you inform family } \\
\text { members about } \\
\text { preventive and } \\
\text { bronchoaspiration } \\
\text { measures? }\end{array}$} \\
\hline Yes, always & $268(82.7)$ & $11(73.3)$ & $44(80.0)$ & $323(81.9)$ & \\
\hline Often & $42(13.0)$ & $4(26.7)$ & $4(7.3)$ & $50(12.7)$ & 0.093 \\
\hline Rarely & $10(3.1)$ & $0(0.0)$ & $5(9.1)$ & $15(3.8)$ & \\
\hline Never & $4(1.2)$ & $0(0.0)$ & $2(3.6)$ & $6(1.5)$ & \\
\hline \multicolumn{6}{|l|}{$\begin{array}{l}\text { Have you witnessed a } \\
\text { bronchoaspiration? }\end{array}$} \\
\hline Yes & $245(75.6)$ & $12(80.0)$ & $44(80.0)$ & $301(76.4)$ & 0.736 \\
\hline Not & $79(24.4)$ & $3(20.0)$ & $11(20.0)$ & $93(23.6)$ & \\
\hline \multicolumn{6}{|l|}{$\begin{array}{c}\text { What was the most } \\
\text { serious result after } \\
\text { witnessing } \\
\text { bronchoaspiration? }\end{array}$} \\
\hline No incidents & $53(16.4)$ & $1(6.7)$ & $19(34.5)$ & $73(18.5)$ & \\
\hline Pneumonia & $153(47.2)$ & $6(40.0)$ & $16(29.1)$ & $175(44.4)$ & \\
\hline Death & $42(13.0)$ & $5(33.3)$ & $10(18.2)$ & $57(14.5)$ & 0.005 \\
\hline $\begin{array}{l}\text { I have not witnessed } \\
\text { any aspiration }\end{array}$ & $76(23.5)$ & $3(20.0)$ & $10(18.2)$ & 89 (22.6) & \\
\hline
\end{tabular}

ANCT: Auxiliary Nursing Care Technician, EAT-10: Eating Assessment Tool, MECV-V: Clinical Examination of Volume Viscosity.

Another question asked was whether screening tests and the diagnosis of liquid dysphagia were carried out in their clinical settings. Up to $20.8 \%(n=82)$ of the subjects reported that the EAT-10 screening test was performed in their centers, whereas $39.2 \%$ $(n=154)$ of the participants did not know the test, with no differences by category of professionals $(p=0.136)$. When faced with the same question in relation to the MECV-V test, $24.1 \%(n=95)$ of the respondents answered that such a test was performed in their clinical setting, and $41.9 \%(n=165)$ reported not knowing it. There were statistically significant differences between the different categories of professionals $(p=0.008)$, as $52.7 \%$ $(n=29)$ of the ANCTs did not know the test compared to $26.7 \%(n=4)$ of the doctors and $40.7 \%(n=132)$ of the nurses.

Up to $41.4 \%$ ( $n=163)$ of the respondents answered that these tests were performed on the population at risk, and only $3.3 \%(n=13)$ on patients after suffering a bronchoaspiration, with no differences in the responses among the different professionals $(p=0.382)$. When asked if there were subsequent controls for dysphagia, 166 (42.1\%) professionals answered positively, and $163(41.4 \%)$ did not know. They were asked who was in charge of performing this test, to which questions, $37.3 \%(n=147)$ of the participants answered that they did not know. Among those who knew the person in charge, the most prevalent response $(35.0 \%, n=138)$ was the nurse, and the respondents who provided this answer were more frequently nurses $(n=117 ; 36.1 \%)$ and ANCTs $(n=19 ; 34.5 \%)$, than doctors $(n=2 ; 13.3 \%)$, although there was no significant difference between professional categories $(p=0.114)$

The results obtained for the management of thickeners showed that $98.8 \%(n=389)$ of the participants reported that thickeners should be used in all liquids, and $1.2 \%(n=5)$ of them answered that they should be used in some of the main meals (breakfast, lunch, dinner), although there were no significant differences between professionals $(p=0.317)$. A high percentage of professionals based their choice of texture on patient tolerance $(n=308$; $78.2 \%)$, with palatability being the factor on which their decision was least based ( $n=18$; $4.5 \%)$. On the other hand, $17.3 \%(n=68)$ of the respondents based their choice on the results of a previous MECV-V test $(p=0.497)$.

Regarding the recommendations that had to be followed for the management of a patient with dysphagia, $92.6 \%(n=365)$ of the participants reported that they always adjusted a patient's position before ingestion. There were statistically significant differences between the different categories $(p<0.001)$, being the percentage of ANCTs that accommodate patients higher than those of nurses and doctors $(98.2 \%$ vs. $92.9 \%$ vs. $66.7 \%$, respectively). In addition, differences were observed in the use and/or recommendation of straw and syringes for the administration of liquids among professionals (ANCT: 76.4\%, 
nurse: $58.6 \%$, and doctor: $60.0 \%, p=0.044)$. In addition, $81.9 \%(n=323)$ of the respondents always provided information to relatives about preventive measures and the management of aspiration $(p=0.093)$.

Lastly, $23.6 \%$ of the professionals surveyed $(n=93)$ had not witnessed a bronchoaspiration. Among those respondents who had witnessed it, $18.5 \%(n=73)$ reported that, after that episode, the patient had no incidents, $44.4 \%(n=175)$ replied that the patient had presented pneumonia, and $14.5 \%(n=57)$ answered that aspiration caused the death of the patient. Significant differences were found among different professional categories $(p=0.005)$.

\section{Discussion}

The management of liquid dysphagia plays an important role in the health care provided by different health professionals and aims to reduce or avoid consequences derived from this dysfunction.

In the study published by Far pour et al. in 2019 [34], it was observed that $96.82 \%$ of the health personnel interviewed knew the definition of dysphagia as a swallowing disorder. This value is higher than that reported in our study $(63.2 \%)$. The aforementioned study was carried out in three university hospitals in three major cities in Iran, so the sample consisted of professionals from three large hospitals, whereas our sample was more dispersed because the professionals surveyed were carrying out their work throughout the national territory, that presents differences in the health system and in the protocols for the management of patients with dysphagia.

The lack of knowledge of the term dysphagia can lead to unjustified practices in these patients, such as the use of fasts or the prohibition of fluid intake, or to indecision about what approach to choose, thus increasing the negative consequences of dysphagia [35].

Although the data on the prevalence of dysphagia reported in the introduction to this article indicated a very high value in the institutionalized elderly population as well as in patients with different neurological diseases, the percentage of health personnel interviewed, working in Neurology departments, who knew the definition of dysphagia was close to $50 \%$, and that of professionals working in health centers was $16.7 \%$. However, the percentage of professionals working in units such as the Emergency department was high, possibly due to the fact that the lack of an adequate diagnosis makes patients go to the Emergency department more often to be treated for the negative consequences of dysphagia.

The early diagnosis of dysphagia helps healthcare professionals to direct care to minimize its risks and consequences. The results obtained showed that only $20.8 \%$ of the subjects in our study stated that the EAT-10 dysphagia screening test was performed in their center, this value being very close $(24.1 \%)$ to the percentage of participants who stated that the MECV-V scanning method was performed. These figures are lower than those reported by Farpour et al., who concluded that between $49.9 \%$ and $52.2 \%$ of the participants in their study had used a method to evaluate or treat dysphagia [35]. These tests should be performed on the entire population at risk, so a higher percentage than that reported in our study (41.4\%) should be achieved.

In the review carried out by Hines et al., it was shown that the detection of dysphagia by nurses improves the management of patients with dysphagia [36]. In our study, a high percentage of nurses declared to conduct the tests, which cabimprove the approach to these patients in our territory.

Thickeners help achieve the texture or viscosity that allows a safe swallowing [37]. The respondents used thickeners in all liquids, and the texture was chosen in relation to the tolerance of the patient, without carrying out an adequate diagnostic test (MECV-V).

Among the recommendations for the management of patients with dysphagia are postural considerations [38]. A high percentage of professionals' report that they adjusted the position of patients with dysphagia before eating, and this percentage was higher for ANCTs and nurses. This may be due to the fact that these professionals provide bedside 
care, which includes the effective and efficient management of the patient's oral route while eating. Sometimes, these professionals are in charge of feeding patients who cannot eat autonomously.

In the protocol published by García et al. in 2018, entitled "Protocol for diagnosis and treatment of oropharyngeal dysphagia in the elderly", it can be seen how the use of straw and syringes should be avoided in elderly patients with dysphagia to prevent aspiration during fluid intake. Our results suggested that a higher percentage of ANCTs provided straws and syringes compared to the nursing staff [39].

The relatives of these patients should be provided with information on preventive measures and management of bronchoaspiration, in order to empower them in the care of their relatives. In our survey, $81.9 \%$ of the respondents reported that they informed family members, but the results described above suggest that this information might be erroneous and, rather than bringing benefits to the patient and the system, it would have consequences negative.

Tracheobronchial aspirations can cause frequent respiratory infections. Up to $50 \%$ of patients with dysphagia can develop aspiration pneumonia, with an associated mortality of up to $50 \%$ [40,41]. Our results show that $76.4 \%$ of the subjects reported having witnessed an episode of aspiration, but $18.5 \%$ of them reported that this episode did not cause any incidence. It should not be forgotten that silent aspiration is one of the main complications that patients present. In this study, $44.4 \%$ of the respondents reported that aspiration resulted in pneumonia, and $14.5 \%$ of them that this pneumonia led to the death of the patient. If we take into account the relative frequencies, that is, with respect tothe total number of aspirations observed, $58.1 \%$ of them resulted in pneumonia, and $32.6 \%$ of these pneumonia occurrences resulted in the death of the patient.

The lack of training of health professionals who provide their services to patients at risk of or with oropharyngeal dysphagia can lead to a delay in patients' diagnosis and increase the complications derived from this condition, which is an important barrier to the management of these patients [42]. Several authors have studied the knowledge possessed by health professionals, mainly nurses, finding that this knowledge was moderate [43] and that specific training and experience in caring for patients with dysphagia provided new and better knowledge [29].

Although the number of responses exceeded the calculated sample size, it is difficult to infer these results, because this study used a convenience sampling rather thana probability sampling. Furthermore, there was a disparity between the number of participants per category and the different geographical areas they came from.

Further research in this field should be carried out, a validated questionnaire developed, and this questionnaire should be presented before and after training, to verify the effectiveness of the training.

\section{Conclusions}

The results of the present study showed that the participants had a moderate/low knowledge of the definition, diagnosis, and clinical management of liquid dysphagia, so necessary tools must be provided for their training in this field. This training must be multidisciplinary and should be directed to all professionals who provide healthcare to patients with liquid dysphagia.

This study shows the need for the implementation of guidelines and/or protocols for the management of patients with dysphagia, with the aim of promoting the training of different health professionals. In addition, it highlights the training needs of these professionals with respect to dysphagia to improve their approach to patients with this condition and allow them to identify the signs of dysphagia, so to refer patients to a qualified specialist.

Author Contributions: Conceptualization: E.S.-S., Y.A.-L., and E.G.-M.; methodology, E.S.-S., Y.A.-L., J.D.-J., and E.G.-M.; software, E.S.-S., Y.A.-L., and E.G.-M.; validation, E.S.-S., Y.A.-L., and E.G.-M.; formal analysis, E.S.-S. and J.D.-J.; investigation, E.S.-S., Y.A.-L. and E.G.-M.; resources, E.S.-S.; data 
curation, E.S.-S. and J.D.-J.; writing-original draft preparation, E.S.-S., Y.A.-L., G.R.-V., J.D.-J., and F.J.O.; writing-review and editing, E.S.-S., G.R.-V., and F.J.O.; visualization, E.S.-S., G.R.-V., and F.J.O.; supervision, E.S.-S. and F.J.O. All authors have read and agreed to the published version of the manuscript.

Funding: This research received no external funding.

Institutional Review Board Statement: Due to the study methodology (national level, voluntary, online survey), approval was not requested by the benchmark Research Ethics Committee ofour center. The study followed the international ethical recommendations contained in the Declaration of Helsinki. Participation in the study was completely free and voluntary. All questionnaires were anonymous, since participants were not asked for any identifying data (name, ID card), so this study complies with the provisions of the Organic Law 3/2018, of December 5, on the protection of Personal Data and guarantee of digital rights).

Informed Consent Statement: Informed consent was obtained from all subjects involved in the study.

Data Availability Statement: The data are collected in a database prepared by the research team.

Acknowledgments: We appreciate all people who collaborated to this project through their participation and the dissemination of the questionnaire.

Conflicts of Interest: The authors declare no conflict of interest.

\section{References}

1. Perez-Cruz, E.; Gonzalez-Munoz, A.; Barrientos-Jimenez, M.; Camacho-Guerra, C.D.; Tapia-Gomez, Y.; Torres-Gonzalez, K.O.; Uribe-Quiroz, G. Evaluación de la disfagia en pacientes con enfermedades neurológicas y su relación con riesgo de desnutrición. Med. Interna De México 2018, 34, 359-365. [CrossRef]

2. Morales Ortiz, A.; Sanchez Galvez, R. Anatomía, fisiológia y fisiopatología de la disfagia en el ictus agudo. In Manual de Nutrición para Pacientes con Ictus Agudo, 5th ed.; Luengo Pérez, L.M., Ramirez Moreno, J.M., Eds.; Luzán: Madrid, Spain, 2011 ; pp. 13-22.

3. Suárez-Escudero, J.C.; Rueda Vallejo, Z.V.; Orozco Andrés, F. Disfagia y neurología: ¿una unión indefectible? Acta Neurol. Colomb. 2018, 34, 92-100. [CrossRef]

4. Bomze, L.; Dehom, S.; Lao, W.P.; Thompson, J.; Lee, N.; Cragoe, A.; Luceno, C.; Crawley, B. Comorbid Dysphagia and Malnutrition in Elderly Hospitalized Patients. Laryngoscope 2021. [CrossRef] [PubMed]

5. Olesen, M.D.; Modlinski, R.M.; Poulsen, S.H.; Rosenvinge, P.M.; Rasmussen, H.H.; Holst, M. Prevalence of signs of dysphagia and associated risk factors in geriatric patients admitted to an acute medical unit. Clin. Nutr. Espen. 2021, 41, 208-216. [CrossRef]

6. Botigué, T.; Masot, O.; Miranda, J.; Nuin, C.; Viladrosa, M.; Lavedán, A.; Zwakhalen, S. Prevalence and Risk Factors Associated With Low Fluid Intake in Institutionalized Older Residents. J. Am. Med. Dir. Assoc. 2019, 20, 317-322. [CrossRef]

7. Waito, A.A.; Tabor-Gray, L.C.; Steele, C.M.; Plowman, E.K. Reduced pharyngeal constriction is associated with impaired swallowing efficiency in Amyotrophic Lateral Sclerosis (ALS). Neurogastroenterol. Motil. 2018, 30, e13450. [CrossRef]

8. Cohen, D.L.; Roffe, C.; Beayan, J.; Blackett, B.; Fairfield, C.A.; Hamdy, S.; Havard, D.; McFarlane, M.; McLauglin, C.; Randall, M.; et al. Post-stroke dysphagia: A review and design considerations for future trials. Int. J. Stroke 2016, 11, 399-411. [CrossRef] [PubMed]

9. Annunziata, A.; Valente, T.; Cauteruccio, R.; Fiorentino, G. Silent dysphagia in two patients with Steinert disease and recurrent respiratory exacerbations. Acta Myol. 2020, 39, 141-143. [CrossRef] [PubMed]

10. Umemoto, G.; Furuya, H. Management of Dysphagia in Patients with Parkinson's Disease and Related Disorders. Intern. Med. 2020, 59, 7-14. [CrossRef] [PubMed]

11. Abubakar, S.A.; Jamoh, B.Y. Dysphagia following acute stroke and its effect on short-term outcome. Niger. Postgrad. Med. J. 2017, 24, 182-186. [CrossRef]

12. Bray, B.D.; Smith, C.J.; Cloud, G.C.; Enderby, P.; James, M.; Paley, L.; Tyrrell, P.; A Wolfe, C.D.; Rudd, A.G. The association between delays in screening for and assessing dysphagia after acute stroke, and the risk of stroke- associated pneumonia. $J$. Neurol. Neurosurg. Psychiatry 2017, 88, 25-30. [CrossRef] [PubMed]

13. Wirth, R.; Dziewas, R.; Beck, A.M.; Clave, P.; Heppner, H.J.; Langmore, S.; Leischker, A.H.; Martino, R.; Pluschinski, P.; Rosler, A.; et al. Oropharyngeal dysphagia in older persons-from pathophysiology to adequate intervention: A review and summary of an international expert meeting. Clin. Interv. Aging 2016, 11, 189-208. [CrossRef]

14. Trimble, J.; Patterson, J. Cough reflex testing in acute stroke: A survey of current UK service provision and speech and language therapist perceptions. Int. J. Lang. Commun. Disord. 2020, 55, 899-916. [CrossRef] [PubMed]

15. Al-Khaled, M.; Matthis, C.; Binder, A.; Mudter, J.; Schattschneider, J.; Pulkowski, U.; Strohmaier, T.; Niehoff, T.; Zybur, R.; Eggers, J.; et al. Dysphagia in Patients with Acuet Ischemic Stroke: Early Dysphagia Screening May Reduce Stroke-Related Pneumonia and Improve Stroke Outcomes. Cereb. Dis. 2016, 42, 81-89. [CrossRef] [PubMed]

16. Sura, L.; Madhavan, A.; Carnaby, G.; Crary, M.A. Dysphagia in the elderly: Management and nutritional considerations. Clin. Interv. Aging 2012, 7, 287-298. [CrossRef] [PubMed] 
17. Ashbaugh, R.A.; Ferrero, I. Nutrición y disfagia. In Tratado de Nutrición. Nutrición y Enfermedad. Tomo IV, 3rd ed.; Gil, A., Ed.; Editorial Médica Panamericana: Madrid, Spain, 2017; pp. 911-989.

18. Joundi, R.A.; Martino, R.; Saposnik, G.; Giannakeas, V.; Fang, J.; Kapral, M.K. Predictors and Outcomes of Dysphagia Screening After Acute Ischemic Stroke. Stroke 2017, 48, 900-906. [CrossRef] [PubMed]

19. Palli, C.; Fandler, S.; Doppelhofer, K.; Niederkom, K.; Enzinger, C.; Vetta, C.; Trampusch, E.; Schmidt, R.; Fazekas, F.; Gattringer, T. Early Dysphagia Screening by Trained Nurses Reduces Pneumonia Rate in Stroke Patients: A Clinical Intervention Study. Stroke 2017, 48, 2583-2585. [CrossRef]

20. Westmark, S.; Melgaard, D.; Rethmeier, L.O.; Ehlers, L.H. The cost of dysphagia in geriatric patients. Clin. Outcomes Res. 2018, 10, 321-326. [CrossRef]

21. Seo, Z.W.; Min, J.H.; Huh, S.; Shin, Y.I.; Ko, H.Y.; Ko, S.H. Prevalence and Severity of Dysphagia Using Videofluoroscopic Swallowing Study in Patients with Aspiration Pneumonia. Lung 2021. [CrossRef]

22. Díaz Fernández, A.I.; González Álvarez, M.A. Prevalencia de disfagia tras Ictus. Visión desde Atención Primaria. Enfermería Comunitaria 2017, 5, 38-56.

23. Burgos, R.; Sarto, B.; Segurola, H.; Romagosa, A.; Puiggrós, C.; Vázquez, C. Traducción y validación de la versión en español de la escala EAT-10 (Eating Assessment Tool-10) para el despistaje de la disfagia. Nutr. Hosp. 2012, 27, 2048-2054. [PubMed]

24. Jorgensen, L.W.; Sondergaard, K.; Melgaard, D.; Warming, S. Interrater reliability of the Volume-Viscosity Swallow Test; screening for dysphagia among hospitalized elderly medical patients. Clin. Nutr. Espen. 2017, 22, 85-91. [CrossRef]

25. Silveira Guijarro, L.J.; Domingo García, V.; Montero Fernández, N.; Osuna del Pozo, C.M.; Álvarez Nebreda, L.; Serra-Rexach, J.A Disfagia orofaríngea en ancianos ingresados en una unidad de convalecencia. Nutr. Hosp. 2011, 26, 501-510. [CrossRef] [PubMed]

26. Guillen-Sola, A.; Marco, E.; Martinez-Orfila, J.; Donaire Mejias, M.F.; Depolo Passalacqua, M.; Duarte, E.; Escalada, F. Usefulness of the volumen-viscosity swallow test for screening dysphagia in subacute stroke patients in rehabilitation income. Neuro Rehabil. 2013, 33, 631-638.

27. Rofes, L.; Arreola, V.; Clavé, P. The volumen-viscosity swallow test for clinical screening of dysphagia and aspiration. Nesté Nutr. Inst. Work. Ser. 2012, 72, 33-42.

28. Ferrero López, M.I.; Rubia Ortí, J.E.; Castellano Vela, E.; González Monte, C.; Sanchis-Bayarri Bernal, V.; Navarro Sanz, R. Los factores relacionados con la mortalidad en pacientes con disfagia ayudan en la toma de decisiones dietéticas y nutricionales. Nutr. Hosp. 2015, 31, 820-828.

29. Rhoda, A.; Pckel-Voight, A. Knowledge of nurses regarding dysphagia in patients post stroke in Namibia. Curationis 2015, 38, 1564. [CrossRef]

30. Patel, B.; Legacy, J.; Hegland, K.W.; Okun, M.S.; Herndon, N.E. A comprehensive review of the diagnosis and treatment of Parkinson's disease dysphagia and aspiration. Expert Rev. Gastroenterol. Hepatol. 2020, 14, 411-424. [CrossRef] [PubMed]

31. Rayhan, R.U.; Zheng, Y.; Uddin, E.; Timbol, C.; Adewuyi, O.; Baraniuk, J.N. Administer and collect medical questionnaires with Google documents: A simple, safe, and free system. Appl. Med. Inform. 2013, 33, 12-21.

32. Ministerio de Sanidad, Consumo y Bienestar Social. Comparaciones internacionales. In Informe Anual del Sistema Nacional de Salud; Ministerio de Sanidad, Consumo y Bienestar Social: Madrid, Spain, 2017; pp. 49-51.

33. Sevilla, B. Número de Auxiliares en Hospitales. España 2015-2017; Statista: Madrid, Spain, 2019; Available online: https:/ / es.statista. com/estadisticas/580365/numero-de-auxiliares-en-hospitales-en-espana/\#statisticContainer (accessed on 15 May 2020).

34. Farpour, S.; Farpour, H.R.; Smithard, D.; Kardeh, B.; Ghazaei, F.; Zafarghasempour, M. Dysphagia management in Iran: Knowledge, attitude and practice of healthcare providers. Dysphagia 2019, 34, 105-111. [CrossRef]

35. Carrión, S.; Cabré, M.; Monteis, R.; Roca, M.; Palomera, E.; Serr-Prat, M.; Rofes, L.; Clavé, P. Oropharyngeal dysphagia is a prevalent risk factor for malnutrition in a cohort of older patients admitted with an acute disease to a general hospital. Clin. Nutr. 2015, 34, 436-442. [CrossRef]

36. Hines, S.; Wallace, K.; Crowe, L.; Finlayson, K.; Chang, A.; Pattie, M. Identification and nursing management of dysphagia in individuals with acute neurological impairment (update). Int. J. Evid. Based Healthc. 2011, 9, 148-150. [CrossRef]

37. Jimenez, I.; Sala, N.; Riera, M.; Herrera, M.V.; Povedano, M.; Virgili, M.N. La opinión del paciente cuenta: Experiencia en la atención nutricional en un equipo multidisciplinar de ELA. Nutr. Hosp. 2015, 31 (Suppl. 3), 56-66. [CrossRef]

38. Ballesteros, M.D.; Palazuelo, L. ¿Y después del ictus, que hacemos para nutrirle? Nutr. Hosp. 2017, 34 (Suppl. 1), 46. [CrossRef]

39. Garcia, E.S.; Olaya-Loor, G.E.; Mateos-Nozal, J. Protocolo diagnóstico y terapéutico de la disfagia orofaríngea en el anciano. Med. Programa Form. Méd. Contin. Acreditado 2018, 12, 3684-3688.

40. Clavé, P.; Verdaguer, A.; Arreola, V. Disfagia orofaríngea en el anciano. Med. Clin. 2005, 124, 742-748. [CrossRef]

41. Barroso, J. Disfagia orofaríngea y broncoaspiración. Rev. Esp. Geriatr. Gerontol. 2009, 44, 22-28. [CrossRef]

42. Tan, L.; Gan, G.; Hum, A.; Lee, A. A Stepwise, mixed-method study approach to identify the barriers to dysphagia care in hospice care nurses. J. Hosp. Palliat. Nurs. 2018, 20, 88-94. [CrossRef]

43. Abu-Snieneh, H.M.; Saleh, M.Y.N. Registered Nurse's Competency to screen dysphagia among stroke patients: Literature review. Open Nurs. J. 2018, 12, 184-194. [CrossRef] 